Turk Med Stud J 2022;9(1):8-13

REVIEW

DOI: 10.4274/tmsj.galenos.2022.09.01.02

\title{
WHAT PHYSICIANS SHOULD KNOW ABOUT COFFEE
}

\author{
Ahmed Adel Khalifa (D) \\ South Valley University, Qena Faculty of Medicine and University Hospital, Department of Orthopedic Surgery, Qena, EGYPT
}

\section{ABSTRACT}

Coffee is one of the most frequently consumed non-alcoholic caffeine-containing beverages. For most physicians, specifically surgeons, morning coffee is considered an integral part of their daily routines. Caffeine is the most studied bioactive constituent of coffee. Coffee and caffeine have beneficial health effects on health, and it has been shown that coffee consumption can assuage the feeling of fatigue, improve alertness, decrease the risk of Alzheimer's disease, induce ergogenic effects, and may be protective against some types of cancer. On the contrary, too much coffee consumption came with side effects, such as tachycardia, increased blood pressure, and decreased bone density. However, most researchers agreed that coffee's benefits outweigh its downsides. In this review, several facts related to coffee consumption will be discussed, including its history, composition distribution, possible physiological effects, ways of serving, and the suggested daily consumption.

Keywords: Coffee, caffeine, physicians

\section{INTRODUCTION}

The sound of the grinding machine, the coffee aroma smell, and the first sip of the morning cup; most coffee lovers start their day with these rituals; owing to its brain alerting effect, coffee has been thought to be a force in scientific development (1). This review aims to provide some insight related to coffee consumption by discussing factors related to coffee history, consumption, composition, possible beneficial physiological effects, ways of serving, and the suggested daily consumption.

\section{HISTORICAL PER SPECTIVE}

The word coffee is believed to originate from an Arabic word, "qahwah," which refers to a particular type of wine and its dark color (2). For at least more than a thousand years, coffee has occupied a very important place in human society. Origins of consumption of coffee probably start from Northeast Africa, which then spread out to the Middle East in the $15^{\text {th }}$ century and from there to Europe; there is some evidence that it was an established drink in the Yemeni Sufi monasteries, from where it spread to other areas (3). Leonhart Rauwolff, a German physician, was the first European to remark coffee, around 1582, on his return from Mesopotamia searching for herbal treatments. He described it as "A perfect drink that is as black as ink and very good in illness, especially of the stomach." (4).

\section{COFFEE CONSUMPTION AMONG VARIOUS NATIONS AND MEDICAL PROFESSIONS}

Coffee is considered one of the most used pharmacologically active non-alcoholic beverages, with its consumption becoming part of regular daily practices of modern life worldwide (1). However, coffee consumption varies among nations; Finland and Norway reported the highest consumption with a mean of $9.6 \mathrm{~kg}$ and $7.2 \mathrm{~kg}$ of coffee consumed per person per year, respectively, while consumption in the United States of America was reported as $3.1 \mathrm{~kg}$ per person per year (5). A Canadian Community Health Survey study reported that coffee comes in second place, the first being water, as the most popular drink among Canadian

Address for Correspondence: Ahmed Adel Khalifa, South Valley University, Qena Faculty of Medicine and University Hospital,

Department of Orthopedic Surgery, Qena, EGYPT

e-mail: ahmed_adel0391@med.svu.edu.eg

ORCID iD of the author: AAK: 0000-0002-0710-6487.

Received: 18.12.2021 Accepted: 03.01.2022

Cite this article as: Khalifa AA. What physicians should know about coffee. Turk Med Stud J 2022;9(1):8-13.

Copyright@Author(s) - Available online at https://www.turkmedstudj.com/ 
adults (6). The National Diet and Nutrition Survey in the United Kingdom demonstrated that a British adult consumes a mean of $130 \mathrm{mg}$ of caffeine per day (7). In contrast, a Japanese adult consumes about $260 \mathrm{mg}$ of caffeine per day (8).

For medical professions, it is generally accepted that surgeons consume more coffee than internists; in a Swiss center retrospective study by Giesinger et al. (4) evaluating coffee consumption of physicians at work and comparing the rate among different specialties ( $n=766$ doctors), they found that $84 \%$ of physicians purchased coffee at least from one of the hospital canteens. Male physicians purchased significantly more cups of coffee per person each year than females $(128 \pm 140$ versus $86 \pm 86, p<0.01)$. Specialty had a significant effect on yearly coffee purchasing $(p<0.01)$, where orthopedic surgeons reported the highest coffee purchase per person per year $(89 \pm 136)$ followed by radiologists $(177 \pm 191)$ and general surgeons (167 \pm 138$)$, while anesthesiologists reported being the least $(39 \pm 48)$. Interestingly, the hierarchical position significantly affected the pattern of purchasing $(p=0.04)$, where senior consultants purchased most cups of coffee per person per year $(140 \pm 169)$ while junior doctors purchased the least (95 \pm 85 ) (4). In a study by Do et al. (9) carried out on 271 Scandinavian anesthesiologists, the authors found that $91.3 \%$ of anesthesiologists were coffee drinkers, with a median of four cups daily. In a study by Tsiga et al. (10), the authors evaluated and compared the health behaviors between three groups, namely police officers, healthcare workers (doctors and nurses), and ambulance workers in Thessaloniki, Greece. The authors found that doctors reported the highest coffee consumption with a mean of $2.26 \pm 1.64$ times per day, followed by nurses who reported consuming coffee $2.02 \pm 1.33$ times per day (10).

\section{THE MAIN COMPONENTS OF COFFEE}

Coffee is composed of a mixture of compounds, with caffeine being the most famous constituent (1). However, coffee is rich in various bioactive substances, which possess a variety of physiological effects. Up to 1,000 phytochemicals were described, including chlorogenic acid, lactones, theophylline, cafestol, niacin, vitamin B3, magnesium, and potassium (11). Caffeine was isolated from coffee beans as early as 1820, and since then, it has been the most investigated component of coffee for its pharmacological potentials and possible clinical applications (12). The amount of caffeine in a cup of coffee is determined by several factors, including first the type of coffee bean, and second the method of preparation. The two most widespread plant species that produce coffee beans are Coffea arabica and Coffea canephora. Researchers found that Coffea canephora contains about twice as much caffeine as
Coffea arabica: 68.6-81.6 versus 34.1-38.5 mg of caffeine per kilogram of dry coffee, respectively (13). The preparation method consists of a number of different variables, brewing water temperature, length of contact time, extraction pressure, bean grind size, and coffee bean roasting method (14). Therefore, while a home-prepared filtered coffee cup contains from 30 to $175 \mathrm{mg}$ of caffeine, one espresso shot contains about 200-300 mg caffeine (15).

\section{THE PHARMACOLOGICAL EFFECTS OF COFFEE COMPONENTS}

After ingestion of coffee, caffeine is absorbed totally in the small intestine in less than one hour, which then diffuses to other tissues (16). Caffeine has a half-life of approximately four to six hours and is metabolized mainly in the liver. Two to three cups of coffee could raise caffeine plasma levels to $20-40 \mathrm{~mol} / \mathrm{L}$; this concentration enables the main action of caffeine as an antagonist of adenosine, which is an endogenous inhibitory neuromodulator leading to drowsiness, fatigue, and sleep (17). As adenosine receptors are present in most tissues, such as the cardiovascular system (CVS), the central nervous system (CNS), liver, muscles, and adipose tissue, what is considered as the physiological effect of coffee is achieved through the blocking action of caffeine on adenosine receptors (14). Another action of coffee is its very potent antioxidant effect exerted through its primary polyphenol content: chlorogenic acid (18).

\section{EFFECTS OF COFFEE ON HEALTH}

Generally, coffee, and its most important content caffeine, is the most used stimulant worldwide, owing to its safety and availability, as studies showed that coffee consumption was generally safe, often associated with more benefit than harm (19). Habitual consumption of coffee has several health benefits, which are shown by epidemiological data: it decreases the risk of neurological diseases (e.g., Parkinson's and Alzheimer's disease) and the development of certain cancers (e.g., hepatocellular, colorectal, and prostatic), as well as positively affecting liver functions and possibly playing a role in weight loss (its lipolytic effect increases metabolic rate and enhances energy expenditure) $(14,20)$. Furthermore, in the meta-analysis by Poole et al. (19) analyzing 201 articles to evaluate the relationship between coffee consumption and health outcomes, they found that consuming three to four cups of coffee per day is beneficial. They showed an association between coffee consumption and reduction in mortality, cardiovascular diseases, as well as neurological and metabolic conditions. In the following sections coffee's effect on various body systems is explained. 


\section{Psychological and Central Nervous System}

Caffeine has a CNS stimulant effect as it crosses the bloodbrain barrier. It acts as an adenosine receptor antagonist; furthermore, it reduces the loss of dopamine and synergizes with noradrenaline, resulting in fatigue sensation reduction and a stimulated perception (21). Some studies showed that caffeine is an effective stimulant for enhancing simple measures of cognitive performance such as alertness and psycho-motor functions even after prolonged periods of sleep deprivation up to 85 hours (22-24). Franke et al. (25) investigated the use of coffee and its derivatives among surgeons, and after analyzing the responses of 951 surgeons they found that $66.8 \%$ reported habitually drinking coffee, and the most common reason for consuming caffeine was to reduce fatigue $(54.3 \%)$, followed by to stay awake working night shifts (32.2\%). A study on surgery trainees by Aggarwal et al. (26) was done using a virtual reality laparoscopic simulator to investigate the effect of caffeine on improving fatigue, as well as technical and neurocognitive skills. Eighteen participants were sleep-deprived and given $150 \mathrm{mg}$ of caffeine on one occasion, and a placebo on another occasion, before performing the simulation laparoscopy. The authors found that after caffeine ingestion, the participants could restore the psychomotor skills to baseline and had a better reaction time compared to the placebo; however, the number of errors between both groups was same.

Coffee consumption was reported to have a protective effect against the development of Parkinson's disease in men and women (27). Moreover, the risk of Alzheimer's and Parkinson's diseases is less in regular coffee consumers $(28,29)$. Interestingly, a study reported that the relative risk of suicide was decreased by $13 \%$ for every cup of coffee consumed daily (29). Some recent studies have concluded a weak protective effect of coffee consumption on the risk of stroke; however, this is still yet to be proven (14).

\section{Endurance Performance and Physical Activity}

It has been estimated that about $74 \%$ of elite athletes usually use caffeine as an ergogenic aid before or during sports, and endurance sports have the highest prevalence rate for caffeine consumption (30). A study showed that acute caffeine ingestion significantly affects endurance performance in the form of an increase in mean power output and faster timetrial times compared to placebo (31).

In a double-blind, randomized study by Church et al. (32) where the authors examined the ergogenic benefits of Turkish coffee taken an hour before exercise, the authors tested performance in a five $\mathrm{km}$ time trial, upper and lower body reaction to visual stimuli after ingestion of either 3.0 $\mathrm{mg}$ caffeine per $\mathrm{kg}$ body weight or decaffeinated coffee; they found that the plasma concentration of caffeine, upper body reaction performance, respiratory exchange rate, and systolic blood pressure, were significantly higher with the Turkish coffee compared to the decaffeinated coffee. They concluded that ingestion of Turkish coffee resulted in better performance and improvement in reaction time and an increase in the feeling of energy. A meta-analysis of randomized controlled trials concluded that caffeine intake lowered the incidence of physical exertion during exercise, leading to longer exercise time (33). Furthermore, caffeine ingestion before prolonged cycling helped reduce muscle pain after exercise (34).

\section{Cardiovascular System}

There is an ongoing controversy regarding the exact effect on the CVS; some suggest that coffee consumption has some adverse effects on serum cholesterol, blood pressure, and plasma homocysteine, whereas others suggest that the effect of caffeine within the coffee on epinephrine concentrations, hyperglycemia, and blood pressure seems to be weaker compared to caffeine taken in isolation $(14,20)$. Acute effects of coffee on the CVS presented as tachycardia, increased blood pressure, and occasional arrhythmia could occur directly after coffee intake; however, these are more profound in susceptible individuals (14). In a study by Bodar et al. (35) evaluating the effect of coffee consumption on atrial fibrillation (AF) development risk including 18,960 United States male physicians having a mean age of 66.1 years, the authors found a lower risk to develop AF among physicians who consumed one to three cups per day.

The association between coffee consumption and higher concentrations of total serum cholesterol and low-density lipoprotein cholesterol was attributed to the diterpene content in coffee oil; however, these compounds are usually removed by paper filters, so consuming filtered coffee may slightly increase serum cholesterol (36). The suggested harmful caffeine effect on the CVS may be neutralized by the benefits offered by other compounds in coffee; the 2015-2020 dietary guidelines for Americans associate the consumption of three to five cups of coffee per day with reduced risk for cardiovascular diseases $(37,38)$.

\section{Digestive System}

Coffee consumption has a protective effect on the liver, helping to prevent the development and progression of liver diseases such as liver cirrhosis and hepatocellular carcinoma (39). This was explained by coffee's ability to lower the levels of liver enzymes (e.g., alanine aminotransferase, aspartate aminotransferase, and gamma-glutamyl transferase) (39). Furthermore, studies have proven no significant relationship between coffee consumption and gastric ulcers, duodenal ulcers, and reflux esophagitis (40). 


\section{Endocrine System}

Studies have shown that the risk of developing type 2 diabetes decreases with regular coffee consumption (41). This protective effect was estimated to be dose dependent, with a $7 \%$ reduction in risk for each additional cup of coffee (41). In contrast, some studies have shown that caffeine alone can lead to impaired glucose tolerance $(14,20)$. However, this effect was also found in decaffeinated coffee, leading researchers to think that even if caffeinated coffee causes a hyperglycemic response $(14,20)$. Other bioactive compounds such as chlorogenic acids and phenolic compounds can neutralize this effect by altering glucose absorption, liver glucose metabolism, and insulin sensitivity $(14,20)$.

\section{Bone Metabolism}

Heavy coffee intake has been associated with increased bone deterioration, lower bone density and the likelihood of fractures $(14,20,40)$. This effect is due to the decrease in the efficiency of calcium absorption in the gastrointestinal tract caused by caffeine. This led dietitians to recommend calcium and vitamin D intake along with limiting coffee intake to 2-3 cups per day to reduce the risk of osteoporosis and related fractures, specifically in older age (42).

\section{Risk of Cancer}

Generally, coffee consumption was associated with a lower risk of different cancers, including those of the liver and colorectum; however, no clear explanation was offered to explain the mechanism (14). It was suggested that caffeine acts as an anti-cancer compound by inhibiting extracellular signal-regulated kinases and $\alpha$-serine/threonine kinases and suppressing matrix-2 metalloproteinase and the $\alpha$-transforming growth factor of cancer-associated fibroblasts (43).

\section{Mortality}

Some studies showed a statistically significant inverse association between coffee consumption and mortality after acute myocardial infarction (44). Compared with non-coffee drinkers, light (1-2 cups per day) and heavy ( $>2$ cups per day) coffee drinkers had a decreased risk of mortality, with the maximum benefit being shown with heavy consumption (44).

\section{DOES COFFEE HAVE SIDE EFFECTS?}

Although caffeine is considered safe, some side effects with its increased use have been reported with variation among subjects according to their metabolism rate, weight, age, and sex (45). These side effects might include tachycardia, jitteriness, agitation, headache, excitability, insomnia, and gastrointestinal tract symptoms, and symptoms of intoxication were reported to occur at a dose of $1,000 \mathrm{mg}$ of caffeine; doses of 3,000 to 10,000 mg might be lethal (46).

Furthermore, caffeine is known for its addictive properties, with a persistent desire to consume caffeine-containing foods or drinks and the possibility of developing withdrawal symptoms when caffeine ingestion is abruptly discontinued (20). Although the matter of being an addictive substance is debatable, some reviews showed that some of the symptoms necessary to diagnose dependency, mainly withdrawal symptoms (headache, fatigue, drowsiness), had been reported in heavy caffeine consumers after stopping intake (47). The explanation behind the appearance of some withdrawal symptoms is that with regular caffeine intake, the adenosine receptor numbers in the CNS increase, which makes individuals more sensitive to adenosine, and with subsequent reduction in caffeine consumption this will potentiate the usual physiological effects of adenosine, resulting in withdrawal symptoms (47).

\section{HOW IS COFFEE PREPARED AND BEST SERVED?}

Generally, coffee is prepared by infusing hot water through the roasted and ground coffee beans. Various methods could be used, such as filtration, percolation, or pressure (39). It could be prepared through various methods: First-Brewed coffee (filter coffee) can be prepared simply by brewing ground coffee beans in hot water and then passing that through a filter to separate the grounds from the brewed coffee. A cup of 8-oz (237 mL) brewed coffee could contain up to 95 to 330 $\mathrm{mg}$ of caffeine (45). Second- Cold brew coffee (different from iced coffee) can be prepared by steeping the coffee grounds in water at room temperature between 8 and 24 hours and then served with ice in it (48). A 12-oz (355 mL) cold brew coffee cup could contain approximately $195 \mathrm{mg}$ of caffeine (49). Third- Instant coffee can be prepared by adding hot water to the granules or coffee powder. It usually has less caffeine compared to freshly brewed coffee. An 8-oz cup of regular instant coffee contains about 30 to $70 \mathrm{mg}$ of caffeine (45). Fourth- Espresso is prepared by forcing hot water or steam through very fine coffee grounds using a machine, stovetop mocha pot, or ready prepared capsules. A single serving of espresso contains about 50 to $150 \mathrm{mg}$ of caffeine (45).

Some research reported that adding sugar to coffee contributes as a risk factor for health problems such as obesity and diabetes, so to keep the health benefits of coffee, adding sugar or sweetener is better avoided $(50,51)$. Studies showed that people who do not add sugar or sweeteners to their coffee had a lower risk of developing depression or metabolic syndrome $(52,53)$. 


\section{HOW MUCH COFFEE SHOULD WE DRINK?}

Moderate daily caffeine intake (about 2 to 4 coffee cups or $300 \mathrm{mg}$ caffeine per day) is generally safe with less CVS stimulatory effects or behavioral changes in a healthy adult, leading to the natural beneficial effects (54). Dyslipidemic individuals might consume filter coffee, as the filters partly retain the main cholesterol-raising compounds in coffee such as cafestol and kahweol (45). People with known high blood pressure or cardiac arrhythmias are advised to limit caffeine intake; while for women planning on getting pregnant, it is better to limit their intake of caffeine to $<300 \mathrm{mg}$ per day (55). Besides, the people at risk of osteoporosis could add two tablespoons of milk to their coffee, which could neutralize the amount of calcium lost per one cup of coffee (55).

\section{CONCLUSION}

Coffee is considered the most consumed beverage worldwide, and it contains various bioactive compounds, with caffeine being the most known and studied component. Coffee consumption is various among nations as well as among various medical specialties, with surgeons and senior consultants ranking as the highest consumers. The health benefits of habitual coffee consumption outweigh its harmful effects. Improving fatigue resistance and alertness, having positive effects on psychomotor functions, reducing Parkinson's risk, protecting against type 2 diabetes, and boosting physical activity were among the health benefits of coffee consumption. However, tachycardia, increase in blood pressure, and withdrawal symptoms were among its side effects. Coffee could be served through various methods: espresso, brewed, instant; and is better served without sugar. It is accepted that two to four cups of coffee per day is generally safe.

Acknowledgments: I would like to sincerely thank Professor Ahmed M. Abdelaal and my friend Dr. Mohamed K. Abdelnasser, who used to buy me a cup of coffee on morning operative lists.

\section{Ethics Committee Approval: N/A}

Informed Consent: N/A

Financial Disclosure: The author declared that this study received no financial support.

\section{REFERENCES}

1. Bae JH, Park JH, Im SS et al. Coffee and health. Integr Med Res 2014;3:189-91. [Crossref]

2. Pendergrast $M$. Uncommon grounds: The history of coffee and how it transformed our world: Basic Books; 2010. [Crossref]
3. Bonita JS, Mandarano M, Shuta D et al. Coffee and cardiovascular disease: in vitro, cellular, animal, and human studies. Pharmacol Res 2007;55:187-98. [Crossref]

4. Giesinger K, Hamilton DF, Erschbamer $M$ et al. Black medicine: an observational study of doctors' coffee purchasing patterns at work. BMJ 2015;351:h6446. [Crossref]

5. Temple JL, Bernard C, Lipshultz SE et al. The Safety of Ingested Caffeine: A Comprehensive Review. Front Psychiatry 2017;8:80. [Crossref]

6. Garriguet D. Beverage consumption of Canadian adults. Health Rep 2008;19:23-9. [Crossref]

7. Fitt $E$, Pell $D$, Cole D. Assessing caffeine intake in the United Kingdom diet. Food Chem 2013;140:421-6. [Crossref]

8. Yamada M, Sasaki S, Murakami $\mathrm{K}$ et al. Estimation of caffeine intake in Japanese adults using $16 d$ weighed diet records based on a food composition database newly developed for Japanese populations. Public Health Nutr 2010;13:663-72. [Crossref]

9. Do HQ, Granholm A, Ellekjaer KL et al. Coffee consumption and work satisfaction among Scandinavian anaesthesiologists: A survey. Acta Anaesthesiol Scand 2019;63:414-7. [Crossref]

10. Tsiga E, Panagopoulou E, Niakas D. Health promotion across occupational groups: one size does not fit all. Occup Med (Lond) 2015;65:5527. [Crossref]

11. Spiller GA. Caffeine. CRC Press; 2019. [Crossref]

12. Schudt C, Hatzelmann A, Beume R et al. Phosphodiesterase inhibitors: history of pharmacology. Handb Exp Pharmacol 2011;(204):146. [Crossref]

13. Jeszka-Skowron M, Sentkowska A, Pyrzyńska K et al. Chlorogenic acids, caffeine content and antioxidant properties of green coffee extracts: influence of green coffee bean preparation. Eur Food Res Technol 2016;242:1403-9. [Crossref]

14. Cano-Marquina A, Tarín JJ, Cano A. The impact of coffee on health. Maturitas 2013;75:7-21. [Crossref]

15. Crozier TW, Stalmach A, Lean ME et al. Espresso coffees, caffeine and chlorogenic acid intake: potential health implications. Food Funct 2012;3:30-3. [Crossref]

16. Levitt DG. Quantitation of small intestinal permeability during normal human drug absorption. BMC Pharmacol Toxicol 2013;14:34. [Crossref]

17. Fredholm $B B$, IJzerman $A P$, Jacobson $K A$ et al International Union of Pharmacology. XXV. Nomenclature and classification of adenosine receptors. Pharmacol Rev 2001;53:527-52. [Crossref]

18. Sato $Y$, Itagaki $S$, Kurokawa $T$ et al. In vitro and in vivo antioxidant properties of chlorogenic acid and caffeic acid. Int J Pharm 2011;403:1368. [Crossref]

19. Poole R, Kennedy OJ, Roderick $P$ et al. Coffee consumption and health: umbrella review of meta-analyses of multiple health outcomes. BMJ 2017;359:j5024. [Crossref]

20. O'Keefe JH, Bhatti SK, Patil HR et al. Effects of habitual coffee consumption on cardiometabolic disease, cardiovascular health, and allcause mortality. J Am Coll Cardiol 2013;62:1043-51. [Crossref]

21. García-Blanco T, Dávalos A, Visioli F. Tea, cocoa, coffee, and affective disorders: vicious or virtuous cycle? J Affect Disord 2017;224:618. [Crossref]

22. Killgore WD, Kahn-Greene ET, Grugle NL et al. Sustaining executive functions during sleep deprivation: A comparison of caffeine, dextroamphetamine, and modafinil. Sleep 2009;32:205-16. [Crossref] 
23. Wesensten NJ, Killgore WD, Balkin TJ. Performance and alertness effects of caffeine, dextroamphetamine, and modafinil during sleep deprivation. J Sleep Res 2005;14:255-66. [Crossref]

24. Benitez PL, Kamimori GH, Balkin TJ et al. Modeling fatigue over sleep deprivation, circadian rhythm, and caffeine with a minimal performance inhibitor model. Methods Enzymol 2009;454:405-21. [Crossref]

25. Franke AG, Bagusat C, McFarlane $C$ et al. The Use of Caffeinated Substances by Surgeons for Cognitive Enhancement. Ann Surg 2015;261:1091-5. [Crossref]

26. Aggarwal R, Mishra A, Crochet $P$ et al. Effect of caffeine and taurine on simulated laparoscopy performed following sleep deprivation. Br J Surg 2011;98:1666-72. [Crossref]

27. Trevitt J, Kawa K, Jalali A et al. Differential effects of adenosine antagonists in two models of parkinsonian tremor. Pharmacol Biochem Behav 2009;94:24-9. [Crossref]

28. de Mendonça A, Cunha RA. Therapeutic opportunities for caffeine in Alzheimer's disease and other neurodegenerative disorders. J Alzheimers Dis 2010;20 Suppl 1:S1-2. [Crossref]

29. Noyce AJ, Bestwick JP, Silveira-Moriyama L et al. Meta-analysis of early nonmotor features and risk factors for Parkinson disease. Ann Neurol 2012;72:893-901. [Crossref]

30. Del Coso J, Muñoz G, Muñoz-Guerra J. Prevalence of caffeine use in elite athletes following its removal from the World Anti-Doping Agency list of banned substances. Appl Physiol Nutr Metab 2011;36:555-61. [Crossref]

31. Southward K, Rutherfurd-Markwick KJ, Ali A. The Effect of Acute Caffeine Ingestion on Endurance Performance: A Systematic Review and MetaAnalysis. Sports Med 2018;48:1913-28. [Crossref]

32. Church DD, Hoffman JR, LaMonica MB et al. The effect of an acute ingestion of Turkish coffee on reaction time and time trial performance. J Int Soc Sports Nutr 2015;12:37. [Crossref]

33. Doherty $M$, Smith PM. Effects of caffeine ingestion on rating of perceived exertion during and after exercise: a meta-analysis. Scand J Med Sci Sports 2005;15:69-78. [Crossref]

34. Gliottoni RC, Meyers JR, Arngrimsson SA et al. Effect of caffeine on quadriceps muscle pain during acute cycling exercise in low versus high caffeine consumers. Int J Sport Nutr Exerc Metab 2009;19:15061. [Crossref]

35. Bodar V, Chen J, Gaziano JM et al. Coffee Consumption and Risk of Atrial Fibrillation in the Physicians' Health Study. J Am Heart Assoc 2019;8:e011346. [Crossref]

36. Jee $\mathrm{SH}, \mathrm{He} J$, Appel LJ et al. Coffee consumption and serum lipids: a meta-analysis of randomized controlled clinical trials. Am J Epidemiol 2001;153:353-62. [Crossref]

37. Chrysant SG. Coffee Consumption and Cardiovascular Health. Am J Cardiol 2015;116:818-21. [Crossref]

38. Voskoboinik A, Koh Y, Kistler PM. Cardiovascular effects of caffeinated beverages. Trends Cardiovasc Med 2019;29:345-50. [Crossref]

39. de Melo Pereira GV, de Carvalho Neto DP, Magalhães Júnior Al et al. Chemical composition and health properties of coffee and coffee byproducts. Adv Food Nutr Res 2020;91:65-96. [Crossref]
40. Shimamoto T, Yamamichi N, Kodashima S et al. No association of coffee consumption with gastric ulcer, duodenal ulcer, reflux esophagitis, and non-erosive reflux disease: a cross-sectional study of 8,013 healthy subjects in Japan. PLoS One 2013;8:e65996. [Crossref]

41. Nawrot $P$, Jordan S, Eastwood J et al. Effects of caffeine on human health. Food Addit Contam 2003;20:1-30. [Crossref]

42. Higdon JV, Frei B. Coffee and health: a review of recent human research. Crit Rev Food Sci Nutr 2006;46:101-23. [Crossref]

43. Niknafs B. Induction of apoptosis and non-apoptosis in human breast cancer cell line (MCF-7) by cisplatin and caffeine. Iran Biomed J 2011;15:130-3. [Crossref]

44. Brown OI, Allgar $V$, Wong KY. Coffee reduces the risk of death after acute myocardial infarction: a meta-analysis. Coron Artery Dis 2016;27:56672. [Crossref]

45. Gonzalez de Mejia E, Ramirez-Mares MV. Impact of caffeine and coffee on our health. Trends Endocrinol Metab 2014;25:489-92. [Crossref]

46. Franke AG, Lieb K. Pharmakologisches Neuroenhancement und "Hirndoping" : Chancen und Risiken [Pharmacological neuroenhancement and brain doping : Chances and risks]. Bundesgesundheitsblatt Gesundheitsforschung Gesundheitsschutz 2010;53:853-9. [Crossref]

47. Juliano LM, Griffiths RR. A critical review of caffeine withdrawal: empirical validation of symptoms and signs, incidence, severity, and associated features. Psychopharmacology (Berl) 2004;176:1-29. [Crossref]

48. Fuller M, Rao NZ. The Effect of Time, Roasting Temperature, and Grind Size on Caffeine and Chlorogenic Acid Concentrations in Cold Brew Coffee. Sci Rep 2017;7:17979. [Crossref]

49. Lane S, Palmer J, Christie B et al. Can cold brew coffee be convenient? A pilot study for caffeine content in cold brew coffee concentrate using high performance liquid chromatography. The Arbutus Review 2017;8:15-23. [Crossref]

50. Te Morenga LA, Howatson AJ, Jones RM et al. Dietary sugars and cardiometabolic risk: systematic review and meta-analyses of randomized controlled trials of the effects on blood pressure and lipids. Am J Clin Nutr 2014;100:65-79. [Crossref]

51. O'Connor L, Imamura F, Brage S et al. Intakes and sources of dietary sugars and their association with metabolic and inflammatory markers. Clin Nutr 2018;37:1313-22. [Crossref]

52. Guo X, Park Y, Freedman ND et al. Sweetened beverages, coffee, and tea and depression risk among older US adults. PLoS One 2014;9:e94715. [Crossref]

53. Kim HJ, Cho S, Jacobs DR Jr et al. Instant coffee consumption may be associated with higher risk of metabolic syndrome in Korean adults. Diabetes Res Clin Pract 2014;106:145-53. [Crossref]

54. Mitchell DC, Knight CA, Hockenberry J et al. Beverage caffeine intakes in the U.S. Food Chem Toxicol 2014;63:136-42. [Crossref]

55. Thomas DR, Hodges ID. Dietary Research on Coffee: Improving Adjustment for Confounding. Curr Dev Nutr 2019;4:nzz142. [Crossref] 